\title{
Attilio Pontanari Maestrini: o precursor da educación física en Compostela no declinar do século XIX
}

\section{(Attilio Pontanari Maestrini: A Precursor of Physical Education in Compostela at the end of the Nineteenth Century)}

\author{
Xosé Luís ANTAS RAMOS \\ Mestre do CEIP Concepción Arenal da Coruña
}

\begin{abstract}
RESUMO: Attilio Pontanari Maestrini foi o precursor da educación física en Compostela; a súa orixe era italiana e alí formárase na escola florentina de ximnasia. En 1879 chegou á Coruña onde coñeceu a Emilia Rodríguez Fariña, coa que se estabeleceu na cidade e formou unha familia. $\mathrm{Na}$ Coruña comezou a exercer de profesor de ximnasia e ortopedista e en 1883 deu a coñecer ese labor en Compostela. Anos despois, un grupo de médicos da Real Sociedade de Amigos do País de Santiago propuxo crear unha escola de ximnasia no seo desa entidade; para organizala e dirixila foi nomeado Attilio Pontanari. A escola foi inaugurada en 1889 e nese mesmo ano instalouse coa súa familia en Compostela, onde tamén puxo en marcha un ximnasio privado. A escola de ximnasia funcionou durante case cinco anos aplicando métodos ximnásticos baseados na forza e a esgrima. En 1893 Pontanari foi nomeado profesor de ximnasia do Instituto de Pontevedra, polo que acabou deixando a súa actividade en Compostela para se trasladar á mencionada cidade.
\end{abstract}

PALABRAS CHAVE: Attilio Pontanari Maestrini; Emilia Rodríguez Fariña; Educación física; Ximnástica; Real Sociedade de Amigos do País de Santiago.

ABSTRACT: Attilio Pontanari Maestrini was the first physical education teacher in Santiago de Compostela. He was born in Italy and studied at the gymnastics school in Florence. Pontanari arrived in Coruña in 1879, where he met his wife, Emilia Rodríguez Fariña. He settled in this city and took on work as a physical education teacher and orthopaedist. In 1883 Pontanari visited Compostela, where he made a presentation of his work. A group of doctors from the Royal Society of Friends of the Country of Santiago proposed the idea of setting up a gymnastics school on the Society's premises. The school was opened in 1889 and Pontanari was appointed director. He moved to Compostela with his family and also set up a private gym. The school was in operation for almost five years and applied gymnastic methods based on strength and fencing. Pontanari was named professor of physical education at the Institute of Pontevedra in 1893 and shortly thereafter he ceased his activities in Santiago and moved to Pontevedra. Physical Education in Compostela began at this school.

KEYWORDS: Attilio Pontanari Maestrini; Emilia Rodriguez Fariña; Physical education; Gymnastics; Royal Society of Friends of the Country of Santiago. 


\section{Presentación}

Attilio Pontanari Maestrini podería ser o protagonista dunha obra do seu amigo ValleInclán. Un hercúleo mestre de esgrima sempre activo e en movemento, dotado de capacidade para a invención e, ademais, dunha singular habilidade para a construción e reparación de aparellos, xa fosen para substituír unha perna amputada xa para pór de novo en marcha unha bicicleta. Así presentado cabe preguntarse se existiu realmente tal persoa e se a súa experiencia vital pode ter algunha vinculación coa historia da educación. Mais o certo é que non só foi o gran precursor da educación física en Compostela, labor ao que daría continuidade despois en Pontevedra e Vigo, senón que a súa figura resulta paradigmática no alborexar dun máis amplo proceso, o da conformación da materia de educación física no sistema escolar.

A pretensión do presente artigo é a de enmarcar a contribución de Attilio Pontanari a ese conxunto de accións, transformacións, iniciativas sociais, propostas políticas etc., que permitiron, tras un longo proceso, que a actividade física e deportiva pasase a formar parte da educación e do día a día da cidadanía. Neste sentido é necesario contextualizar os pasos dados para a incorporación da educación física ao ensino nos anos finais do século XIX e, ao mesmo tempo, aqueles aspectos da traxectoria persoal e profesional de Pontanari que formaron parte dese proceso (deixando á marxe outros moitos elementos da súa, sen dúbida, vibrante biografía). ${ }^{1}$

\section{Cara ao desenvolvemento da educación física}

No ano da publicación do Emilio de Rousseau, 1762, a expresión educación física foi empregada por primeira vez polo médico e hixienista suízo Jean Ballexserd (17261774), na súa obra Dissertation sur l'éducation physique des enfants depuis leur naissance jusqu'à l'âge de leur puberté. ${ }^{2}$ Se ben na súa primeira acepción a mencionada expresión non facía referencia á formación corporal -senón que remitía á idea de protexer e conservar as funcións orgánicas- certamente a educación física xurdiu ao carón do naturalismo rousseauniano, da súa posta en práctica por Johann Bernhard Basedow (1723-1790) no Philanthropinum de Dessau en 1774, e da concreción dese pensamento no labor educativo de Johann Heinrich Pestalozzi (1746-1827).

Estas correntes de pensamento propiciaron a reflexión pedagóxica arredor da educación corporal como elemento necesario dentro dunha concepción máis ampla, a da formación integral da persoa, e deron lugar a diversos movementos ximnásticos e propostas

\footnotetext{
${ }^{1}$ En relación coa figura de Attilio Pontanari Maestrini: Miguel Ángel López Fariña, «La Escuela de Gimnasia de la RSEAP de Santiago", Memoria 2011 Real Sociedad Económica de Amigos del Pais de la Ciudad de Santiago, (2011): 77-89 (http://www.economicadesantiago.org/gestion/descargas/docs/Memoria\%202011\%20(53-96). pdf); Miguel Ángel López Fariña, "Attilio Pontanari y la ciudad de Pontevedra», Memoria 2016 Real Sociedad Económica de Amigos del Pais de la Ciudad de Santiago, (2016): $73-96$ (http://www.economicadesantiago.org/ gestion/descargas/docs/RSEAPS\%20memoria\%202016.pdf); e Amador Montenegro López, Notas para una historia íntima de Vigo (Vigo: 0 autor, 1990), 318-320.

${ }^{2}$ Conrad Vilanou, «Contexto histórico y antecedentes de la educación física», Tándem La educación física hacía el siglo XXI, no. 1 (2000): 39-51.
} 
que incorporaban o xogo deportivo. 0 alento pedagóxico estendeuse progresivamente por Europa para dar lugar a experiencias educativas diferenciadas en distintos momentos, segundo a evolución de cada estado e o nivel de intercambio e mutuo coñecemento das propostas desenvolvidas neles. En todo caso, foi a práctica da ximnasia a que conformou o espazo da educación corporal, agás no caso da escola inglesa, que evolucionou arredor do xogo deportivo.

En España podemos falar dun precedente da educación física que data do ano 1785, momento en que foi aprobado o plan de estudos do denominado Seminario de Nobles que incluía o baile, a música, a esgrima e a equitación -este foi elaborado en 1783, mentres ocupaba a dirección do centro o brigadier Antonio Angosto-. Non obstante, a xénese da ximnasia escolar debemos situala no Real Instituto Militar Pestalozziano, institución creada en 1805 e posta en funcionamento un ano máis tarde en Madrid, que tivo de valedor a Francisco Amorós Ondeano. O sistema pestalozziano fora promovido pola Real Sociedad Cantábrica de Amigos del País de Santander, baixo o influxo do seu secretario e gran coñecedor da obra de Pestalozzi, o presbítero Juan Andújar. O seu método espertou 0 interese de Amorós quen, ademais de impulsar o centro, asumiu, pouco despois da súa apertura, a responsabilidade da dirección. ${ }^{3}$

O exilio de Francisco Amorós pola súa condición de «afrancesado» levouno a ser a principal figura do movemento ximnástico no país veciño, alén dos Pireneos. Mentres, en España, foron Francisco de Aguilera Becerril, conde de Villalobos, e singularmente José María Aparici Biedma, seguidor do método amorosiano, os que continuaron co desenvolvemento da ximnasia a este lado da cordilleira. ${ }^{4}$ En todo caso, 0 avance dos métodos e a práctica ximnástica en España non tiveron o pulo que acadou noutros países europeos, dinámica que tamén podemos facer extensiva á súa incorporación ao ensino. Cabe salientar a existencia de iniciativas como a do médico e pedagogo Pablo Montesino, que nos seus traballos contemplou a faceta física dentro da idea de educación integral e influíu para que formase parte do regulamento de 1842 da Escuela Normal de Madrid. E no eido institucional a do ministro viveirense Nicomedes Pastor Díaz que no plan de estudos posto en marcha en 1847 incorporou a disciplina de ximnástica no segundo ensino; ou a do tamén galego Eduardo Chao durante a efémera I República. Mais estas tentativas de abrir espazos á formación corporal no ensino, así como outras posteriores, non chegaron a xermolar. ${ }^{5}$

O punto de inflexión para a incorporación da formación corporal ao ensino márcao a proposición de lei defendida en 1881 por Manuel Becerra Bermúdez. Antes resultaran frustrados varios precedentes e un intento de defensa da mesma proposición, mais nesta oca-

\footnotetext{
${ }^{3}$ Antonio Viñao Frago, Política y educación en los orígenes de la España contemporánea. Examen especial de sus relaciones en la enseñanza secundaria (Madrid, Siglo XXI de España Editores, 1982), 60-61, 71-72.

${ }^{4}$ lbídem, 251-258.

${ }^{5}$ Vid. Federico Gómez Rodríguez de Castro, «El currículo de la formación del maestro (El momento histórico de la creación de las Normales en España) (1834-1857)", Historia de la Educación, Revista Interuniversitaria, no. 5 (1896): 159-176. Vid. Real decreto do 8 de xullo de 1847.
} 
sión o debate abriu paso a unha comisión presidida por Manuel Becerra que incorporou unha modificación substancial, a creación da denominada «Escuela Central de profesores y profesoras de Gimnástica». ${ }^{6}$ A lei promulgouse, finalmente, 09 de marzo de 1883, aínda que é importante subliñar que non contou coa adhesión dos sectores máis progresistas do país pola orientación ximnástica que se estaba a propugnar, tomada dos modelos baseados na introdución dos exercicios de instrución militar nos centros escolares. Fronte a este modelo, os representantes da ideoloxía do liberalismo progresista, e sinaladamente aqueles vinculados ao influxo pedagóxico da Institución Libre de Enseñanza, defendían unha práctica física dirixida á formación integral do individuo. Propoñían unha praxe afastada da rixidez dos métodos ximnásticos, que prestase especial atención ás prácticas ao aire libre, ao excursionismo e ao sport inglés, pero, sobre todo, que erradicase os exercicios militares escolares. $^{7}$

O desenvolvemento da lei resultou parcial e sempre baixo o empuxe de gobernos liberais. A Escuela Central, situada en Madrid e creada en abril de 1887, entrou en funcionamento no mes de outubro e mantívose activa durante cinco anos -0 30 de xuño de 1892 foi clausurada ao suprimir dos orzamentos, un novo goberno presidido por Cánovas, o crédito que se lle viña asignando-. Nese centro, que segundo afirma Martínez Navarro «rezumaba intelectualismo, teoría y una clara vinculación a las más rancias escuelas gimnásticas atlético-militares", tituláronse un total de dezasete mulleres e oitenta homes. ${ }^{8}$

Finalmente, as clases de Ximnástica tomaron forma nos institutos cabeza de distrito universitario, sobre o papel, en xullo de 1892; e na práctica, coa real orde de setembro de 1893, que ampliaba a súa implantación aos institutos provinciais e recollía o seu orzamento. ${ }^{9}$ Cumpríase, así, o mandato de incorporar a disciplina e o compromiso adquirido co profesorado formado na clausurada Escuela Central. Tamén quedou aberta a posibilidade de que as vacantes que non fosen cubertas polo profesorado titulado puidesen ser desempeñadas interinamente por aquelas persoas que posuísen aptitudes e profesións acordes coa disciplina, aínda que sen especificar cales eran estas. Con posterioridade, regulouse un procedemento para o acceso ao título de profesor de Ximnástica consistente nun exame de reválida que comprendía dous exercicios, un teórico e outro práctico. En 1897 foi convocado e desenvolvido pola Universidade Central. ${ }^{10}$

Veremos posteriormente que tanto ese contexto social e político, que reflicte unha reflexión de fondo sobre a formación corporal, como o marco desenvolvido para a súa

\footnotetext{
${ }^{6}$ Vid. Salvador López Gómez, Breve reseña histórica de la Gimnástica en Europa (Sevilla: Juan Moyano, 1881). 7 Vid. Manuel Bartolomé Cossío, "Contra la introducción de los ejercicios militares y batallones escolares en la escuela», BILE, no. 272 (1888): 145-147.

${ }^{8}$ Anastasio Martínez Navarro, «Datos para la historia de una iniciativa fallida: la Escuela Central de Gimnástica», Historia de la Educación, Revista Interuniversitaria, no. 14-15 (1995-96): 125-149.

${ }^{9}$ Real decreto do 26 de xullo de 1892, Gaceta de Madrid do 30 de xullo, no. 212 (1892): 408-423; e Real orde do 1 de setembro de 1893, Gaceta de Madrid do 10 de setembro, no. 253 (1893): 969.

${ }^{10}$ Real orde do 11 de maio de 1897, Gaceta de Madrid do 16 de maio, no. 136 (1897): 577; e Real decreto do 14 de outubro de 1896, Gaceta de Madrid do 16 de outubro, no. 290 (1896): 177.
} 
realización práctica, tiveron no contexto da Compostela do século XIX unha singular concreción.

\section{Attilio Pontanari Maestrini}

Attilio Pontanari Maestrini naceu o 21 de agosto de 1851 e era natural de Florencia, provincia da Toscana. Na súa Italia natal, na escola de ximnasia florentina, obtivo o título de mestre con medalla de prata 08 de outubro de 1876. Tamén no país transalpino foi nomeado socio de honra do Círculo Italiano do Progreso das Artes, Ciencias, Industria e das Letras 08 de abril de 1879. ${ }^{11}$ Un mes máis tarde temos noticia da súa presenza na Coruña, como figura destacada do Circo Ecuestre de Rafael Díaz. ${ }^{12}$ Se ben descoñecemos as circunstancias polas que viaxou a Galiza, a súa presenza no circo non debe estrañarnos, dado que foi precisamente a súa area un espazo de liberdade para o cultivo das prácticas físicas. Tanto e así que Adolfo Revuelta Fernández, a persoa que a partir de 1903 daría continuidade ao labor de promoción física iniciado por Attilio Pontanari en Compostela, afirmaba en 1894 nunha das obras de referencia da época, o Tratado racional de Gimnástica de José Esteban García Fraguas, que «Si el Circo ha conservado la afición, / el Circo ha extraviado la opinión». ${ }^{13}$

Á pista do circo regresou anos máis tarde Pontanari para mostrar o traballo desenvolvido como profesor -cuestión sobre a que volveremos- pero baixo a carpa só estivo de paso. O novo veciño italiano pronto pasou a formar parte da sociedade coruñesa e a exercer no ámbito en que se formara en Florencia; deixou constancia deste feito a sociedade Liceo Brigantino da Coruña ao concederlle 01 de agosto de 1881 a «medalla de oro con diploma de Socio de mérito, como Director de gimnasia y esgrima de la misma». ${ }^{14}$

A razón pola que se instalou na cidade foi a relación sentimental xurdida entre Emilia Rodríguez Fariña e el. Vínculo que nunca chegaron formalizar legalmente e mantiveron até o pasamento de Attilio Pontanari o 24 de outubro de 1924, cando residían en Vigo. A parella tivo dúas fillas, Gloria, nacida en agosto de 1880, e Eva, en xuño de 1882; ambas na Coruña. ${ }^{15}$

A súa actividade docente comeza en 1882, ao ser nomeado profesor de Ximnasia Hixiénica do Colexio Católico da Coruña. Dous anos máis tarde, no mes de maio, asume tamén a responsabilidade desas mesmas clases na Casa de Misericordia, dependente da deputación provincial, posto que pasou a ocupar en propiedade 029 de abril de 1885. 0 traballo de profesor non lle impide desenvolver outras facetas $e$

\footnotetext{
${ }^{11}$ Expediente persoal de Attilio Pontanari Maestrini, Arquivo Xeral da Administración (en diante AXA), Sección educación, Caixa 32/8440, atado 5859-3.

12 Vid. López Fariña, «La Escuela de Gimnasia...», 77-89.

${ }^{13}$ Adolfo Revuelta Fernández, "La gimnasia artística», en José Esteban García Fraguas, Tratado racional de Gimnástica y de los ejercicios y juegos corporales (Teoría y práctica de los ejercicios gimnásticos y del Sport), Madrid, Casa editorial y librería de la Viuda de Hernando y Compañía, 1894, tomo II, 560-635.

${ }^{14}$ Expediente persoal de Attilio Pontanari Maestrini, AXA, Sección educación, Caixa 32/8440, atado 5859-3.

15 Vid. López Fariña, «Attilio Pontanari...», 73-96.
} 
o 7 de xaneiro de 1885 é nomeado polo hospital da Coruña construtor de «aparatos ortopédicos y clínicos». ${ }^{16}$

O labor na Coruña de Attilio Pontanari comezou a ser coñecido noutros lugares de Galiza desde moi cedo. No mes de novembro de 1883 o florentino visitou Compostela, feito que recolleu o diario Gaceta de Galicia, que daba conta nun editorial da súa presenza na cidade en calidade de director do ximnasio da Coruña. O xornal destaca que os redactores tiveron ocasión de observar diversos aparellos «para corregir las deformidades que pueden ocurrir en el individuo». Afírmase tamén que Pontanari foi convidado a fundar un ximnasio en Compostela, ao tempo que se lle aseguraba que sería todo un éxito debido a que na cidade concorría «la mayor parte de la juventud gallega». ${ }^{17}$



Attilio Pontanari Maestrin

${ }^{16}$ Expediente persoal de Attilio Pontanari Maestrini, AXA, Sección educación, Caixa 32/8440, atado 5859-3.

17 «El Gimnasio», Gaceta de Galicia, 5 de novembro (1883): 1. 
O editorial resulta revelador no que respecta á actividade profesional de Pontanari e os seus primeiros contactos coa sociedade compostelá, mais o seu verdadeiro valor é outro, xa que radica na súa reflexión de fondo e na súa busca de xerar estado de opinión. 0 texto de Gaceta de Galicia reflexiona sobre como a falta dun desenvolvemento corporal axeitado provocaba que se resentise a xeración da época e salienta que para paliar esa carencia era necesario empregar os medios e recursos que a "ciencia nos presente» como así se fai noutras cidades. Tamén apunta o xeito de pór a ciencia ao servizo dese obxectivo, que era a través da apertura dun ximnasio hixiénico ao que puidese acudir a mocidade a completar o seu desenvolvemento; sen esquecer comprometer o seu aplauso co goberno que implantase a ximnasia hixiénica nos institutos.

Attilio Pontanari foi partícipe do interese que espertaba en Compostela, cando menos en certos sectores, tanto a apertura dun ximnasio como, en xeral, aqueles temas relacionados coa actividade física e o desenvolvemento corporal. A visita permitiulle dar a coñecer na cidade o labor de ortopedista que levaba tempo desenvolvendo na Coruña e con ese fin publicou nas seguintes semanas un anuncio, en Gaceta de Galicia, no que se presentaba como «Profesor Gimnástico y Ortopedista de Florencia». ${ }^{18}$

Os anos posteriores á súa visita a Compostela Pontanari continuou coa súa actividade na Coruña. Emporiso, nalgún momento regresou ao seu país natal e residiu durante algún tempo en Venecia. 015 de febreiro de 1888 foi nomeado inspector dos asilos nocturnos desa cidade e un mes despois foi designado membro do tribunal de honra contra os duelos polo Círculo de Esgrima Veneciano. Durante a súa estadía realizou un curso de tiro ao branco na Escola Militar de Venecia, que rematou 09 de xuño do mesmo ano. Once días despois, 020 de xuño, foi nomeado «Profesor de gimnástica higiénica y terapéutica de la Sociedad Económica de Santiago».19

\section{A chamada compostelá a Attilio Pontanari}

No contexto perfilado até agora conflúen elementos da reflexión pedagóxica, da formación corporal, da dimensión hixiénica, da idea de desenvolvemento económico e social, e do pensamento liberal decimonónico. Nese marco xermolaron múltiples iniciativas que no seu conxunto conformaron unha forza de progreso; as máis delas agromaron arredor do que denominamos institucionismo, isto é, vinculadas ás propostas educativas da Institución Libre de Enseñanza. De entre aquelas que en Galiza xiraron arredor da educación física, sobre as que xa ten reflexionado o historiador Ricardo Gurriarán, a impulsada pola Real Sociedade Económica de Amigos do País de Santiago (en diante RSEAP) resultou en moitos sentidos pioneira. ${ }^{20}$

\footnotetext{
${ }^{18}$ Gaceta de Galicia, 7 de novembro (1883): 3.

${ }^{19}$ Expediente persoal de Attilio Pontanari Maestrini, AXA, Sección educación, Caixa 32/8440, atado 5859-3.

${ }^{20}$ Ricardo Gurriarán Rodríguez, "O influxo do institucionismo na Educación Física. As primeiras iniciativas en Galicia (1890-1936)", en M. a José Mosquera González e Rafael Martín Acero (editores), 20 anos do INEF de Galicia (1986-2006) (A Coruña: INEF-Galicia, 2006), 42-70.
} 
A iniciativa para a creación dunha clase de Ximnasia Hixiénica na RSEAP xurdiu en 1886. Máis concretamente 023 de outubro, momento en que os socios e médicos Juan Barcia Caballero, Valentín García Reboredo, Isidoro Casulleras e Isidoro Sánchez Salgués propuxeron á «Sociedad la creación en sus escuelas de una clase de gimnasia higiénica, como elemento indispensábel para la educación física de la juventud». No seu escrito, como vemos na cita tomada do primeiro parágrafo da súa proposición, identifícase a ximnasia hixiénica coa educación física. Tal concepción alcanza todo o seu significado cando, ao xustificar a súa iniciativa sinalando as vantaxes da ximnasia, non se limitan a subliñar aspectos físicos como o robustecemento do organismo ou a adquisición de forza, axilidade e destreza, senón que apuntan o feito de que ese desenvolvemento físico «inspira serena confianza». Están a amosar, de xeito explícito, unha visión integral da persoa, necesitada, en consecuencia, dun proceso formativo que atenda todas as súas dimensións e proporcione un desenvolvemento global..$^{21}$

Os redactores da proposición, en consonancia coa súa visión da educación, fan desde o principio do seu escrito unha chamada de atención sobre a «urgente» necesidade de introducir o ensino da ximnasia. Mais no seu caso incorporan unha cuestión de fondo de capital importancia: a formación ximnástica debe pasar a formar parte dos centros educativos e, tamén, dos nosos costumes. Vólvese albiscar o avanzado do seu pensamento ao vincular, como instrumento de progreso, o ensino e o desenvolvemento de hábitos persoais e sociais.

No que respecta ao modelo de ximnasia proposto, a referencia é a da «educación física sólida é higiénica de los alemanes", impulsado naquel país, segundo sinalan, por unha profusa rede de ximnasios públicos e particulares. Para xustificar a elección da ximnasia alemá destacan como características dos prusianos a robustez, a tenacidade e a constancia; percíbese de novo a idea de desenvolvemento integral da persoa, pois fan sobresaír, como froito da práctica da educación física, aspectos físicos e tamén de carácter.

A modo de colofón, para finalizar a argumentación en defensa da proposta, ensaian unha definición do concepto de ximnasia. Primeiro, rexeitando a visión da súa práctica como recreo inútil ou distracción e, despois, afirmando que na súa condición de rama da hixiene conforma unha arte metódica de aplicación, base fundamental da educación física.

Para dar resposta á iniciativa a RSEAP tomou a decisión de reunir unha comisión que elaborase un informe sobre a proposta. Os responsábeis dese labor foron Maximino Teijeiro, Antonio Fernández Chacón, Emilio Méndez Brandón e Antonio Otero, cuxas conclusións quedaron recollidas nun escrito asinado o 31 de xullo de 1887 e presentadas na sesión que tivo lugar 03 de agosto. Os autores do informe apoian clara e firmemente a proposta de incorporar as clases de ximnasia creando unha sección dedicada a esta ensinanza. Para eles a educación física era máis que conveniente e necesaria, era «indispensable», polo que resultaba incomprensíbel que, do mesmo xeito que se

${ }^{21}$ "Gimnasia higiénica", Revista de la Sociedad Económica de Amigos del País de Santiago, no. 73, 74, 75, 76, 77 e 78 (1888): 650-652. 
prestaba atención ao progreso e aos avances da ciencia, non ocupase un papel central en proporción ao seu valor. ${ }^{22}$

A comisión basea a súa defensa da importancia da educación física nunha concepción integral do ser humano. Sinálao de xeito explícito ao falar dos avances logrados ao longo do século; dado que se ben a intelixencia voou buscando novos horizontes, cabe preguntarse en que medida ese poderoso empuxe recaeu na "educación psíquica, en detrimento de la orgánica». Ademais, como xustificación da súa práctica apuntan unha «razón poderosa» ante a que enmudece o resto, a razón hixiénica. De feito, a orientación médica do informe resulta bastante acusada -Maximino Teijeiro e Fernández Chacón eran licenciados en Medicina, Méndez Brandón e Antonio Otero en Dereito-e para soster a súa argumentación recorren á "ciencia médica» que, segundo destacan, amosa tal interese polo tema que se podería aseverar que cada médico é un apóstolo da ximnasia. ${ }^{23}$

Como conclusión, o documento recomenda aceptar e pór en práctica de inmediato a proposición examinada, e incorpora unha previsión do custo económico, "de mil a dos mil pesetas", para atallar posíbeis obxeccións. Deste xeito a RSEAP contaría cun modesto estabelecemento que respondería ás necesidades expostas e que resultaría «higiénico y recreativo". Neste último apuntamento queda recollida unha dimensión da ximnasia, a recreativa, á que non se fixera mención previamente, pero que tamén estivo presente nas consideracións dos membros da comisión.

Tanto a proposta como o informe que a valora representan dúas reflexións vangardistas e innovadoras, pois son varias as características que reúnen e as fan merecedoras deses cualificativos. A utilización do concepto de educación física para facer referencia á ximnasia e á educación corporal implica adiantarse, máis de dúas décadas, á xeneralización do uso dunha terminoloxía que denota a busca dun espazo encamiñado á formación corporal do individuo; ámbito de maior complexidade que o simple adestramento ou a mera práctica física. A proposta de organización dunha clase que pretendía compensar as deficiencias e limitacións da realidade educativa da época en Compostela, representa outro trazo de progreso e modernidade. O compromiso co ben común e a preocupación polo progreso, non só dos individuos senón tamén dos pobos, que impulsa a proposta, forma parte da esencia do liberalismo e, en certa medida, encerra xa elementos do que a partir da crise do 98 coñecemos como rexeneracionismo. A orientación da acción educativa cara á educación integral ou, dito doutro xeito, o equilibrio entre a formación mental e corporal expresado pola comisión, é outra característica que nos amosa 0 avanzado desta iniciativa.

\footnotetext{
${ }^{22}$ Ibídem.

${ }^{23}$ Maximino Teijeiro Fernández (Monforte, 1827-Compostela, 1900) foi unha destacada figura do monterismo, ademais de ser institucionista e masón. Cabe salientar que traballou para «aproximar a Facultade de Medicina de Santiago [...] ás ciencias positivas innovadoras e á modernidade»; Ricardo Gurriarán, Ciencia e conciencia na Universidade de Santiago (1900-1940): do influxo institucionista e a JAE á depuración do profesorado (Santiago de Compostela: Universidade, Servizo de Publicacións e Intercambio Científico, 2006), 72-78.
} 
Para a posta en funcionamento da escola de ximnasia, o primeiro paso dado pola RSEAP foi nomear a Attilio Pontanari responsábel da nova sección. No verán de 1889 o profesor florentino comezou cos labores de acondicionamento do ximnasio no edificio compostelán de San Clemente. A principios de xullo organizou o traslado, desde Barcelona a Galiza no vapor Dano, dos «aparatos Gimno terápicos» da súa propiedade con destino á aula. Nas mesmas datas desprazouse tamén a Vilagarcía e Carril a mercar cordas e outros obxectos complementarios. ${ }^{24}$ Ao comezo do novo curso a prensa local anunciou que o día 7 de outubro serían inauguradas as clases da RSEAP. Na noticia facíase mención específica á clase de ximnasia, salientando o número «crecido de alumnos» co que xa contaba; e a Attilio Pontanari, mencionando as especiais «dotes que adornan» ao profesor. ${ }^{25}$

Desde 1889 até 1893 o mestre italiano dirixiu as clases da escola de ximnasia e iniciou no eido da educación corporal ao seu alumnado, tanto rapazas coma rapaces. Para a RSEAP a actividade desenvolvida durante eses anos por Attilio Pontanari respondeu sempre ao seu recoñecido "celo", competencia e laboriosidade, o que propiciou que obtivese adiantos moi notábeis co alumnado que tivo baixo a súa dirección. Esta valoración foi recollida e certificada pola propia RSEAP a petición do seu profesor en 1893, momento en que se incorporou a disciplina de Ximnástica ao segundo ensino. 0 motivo polo que se expide o documento hai que buscalo na regulamentación do acceso ás novas cátedras que, como xa se apuntou, permitía o seu desempeño de xeito interino sempre que se posuísen aptitudes e profesións acordes coa materia. O profesor Pontanari alegou a súa experiencia docente, ademais doutros méritos, ao solicitar a súa participación no concurso ás prazas dos institutos de Santiago, A Coruña, Pontevedra, Ourense e Lugo. ${ }^{26}$

O 21 de setembro de 1893 o mestre italiano foi nomeado profesor interino do Instituto de Pontevedra, praza da que tomou posesión uns días máis tarde, 04 de outubro. As súas novas responsabilidades profesionais fixeron que a partir de decembro deixase frecuentemente sen atender as clases da escola de ximnasia da RSEAP. Como consecuencia, as clases quedaron practicamente sen alumnado o curso 1894-95 e, finalmente, en outubro de 1895, xa sen ningunha matrícula, Attilio Pontanari presentou a súa renuncia. ${ }^{27}$

O que xurdira como un proxecto senlleiro e consolidara a primeira experiencia de educación física en Compostela esmoreceu, aínda que a RSEAP o puido reactivar case unha década despois cun novo profesor, Adolfo Revuelta Fernández. O responsábel da nova etapa, trasladado ao Instituto de Santiago en 1903, foi anos máis tarde un dos principais renovadores do ensino da materia, até o punto de gañarse o apelativo de Tissié español -en alusión ao médico francés Philippe Tissié- ${ }^{28}$

\footnotetext{
${ }^{24}$ Gaceta de Galicia, 9 de xullo (1889): 2; e 13 de xullo (1889): 2-3. Segundo recolleu a Gaceta de Galicia, a inauguración da escola de ximnasia estaba prevista para o 25 de xullo, o que a faría coincidir co día grande das festas da cidade. É posíbel que efectivamente tivese lugar o dito acto, mais de ser así tivo que ser simbólico dado que os aparatos que se ían instalar saíron de Barcelona 017 de xullo.

${ }^{25}$ Gaceta de Galicia, 5 de outubro (1889): 2.

${ }^{26}$ Expediente persoal de Attilio Pontanari Maestrini, AXA, Sección educación, Caixa 32/8440, atado 5859-3.

${ }^{27}$ Vid. López Fariña, «La Escuela de Gimnasia...», 77-89.

${ }^{28}$ "Homenaje a Revuelta», El Compostelano, 29 de maio (1928): 1.
} 
A presenza de Attilio Pontanari en Compostela queda circunscrita á primeira etapa da escola de ximnasia da RSEAP, non obstante a súa actividade na cidade foi ampla e variada. Antes de analizar o modelo de formación corporal que puxo en práctica durante os anos en que exerceu de director desa escola, cabe deterse brevemente noutras das súas facetas durante ese período.

Ao mesmo tempo que a RSEAP preparaba a apertura da súa sección de ximnasia, o seu profesor puxo en funcionamento unha sala de esgrima que, segundo informou a prensa, contaba con todos os adiantos que até o momento se coñecían, singularmente os relativos á «escuela italiana». ${ }^{29}$ As súas instalacións estaban situadas no número un da rúa das Orfas e comezou a funcionar no verán de 1889. A historia desta sala acabou sendo coñecida máis que polo seu profesor, por un célebre alumno, Ramón María del Valle-Inclán; a amizade xurdida foi máis coñecida na etapa pontevedresa de Pontanari, pois ambos celebraron asaltos a puñal e a espada dos que deu conta a prensa. ${ }^{30}$

Outro centro en que o profesor florentino exerceu a docencia, tamén a partir de setembro de 1889, foi o colexio de primeiro e segundo ensino San Luis Gonzaga, situado no número 23 da rúa Nova. Pero Attilio Pontanari era realmente un home polifacético; en 1890 creou unha sociedade de Bombeiros Voluntarios en Compostela, que se estabeleceu no número 56 da rúa do Franco, e da que foi nomeado director 027 de abril. Tamén foi un grande impulsor do ciclismo, xunto o outro destacado valedor desta práctica na cidade, Mariano Fernández Tafall, administrador do xornal Gaceta de Galicia. Xuntos organizaron unha viaxe a Porto que denominaron «50 leguas en bicicleta» e que, unha vez iniciada na madrugada do domingo 5 de xullo de 1891, serviu para popularizar o ciclismo a través das crónicas publicadas por Gaceta de Galicia. Nelas destácase a pericia do «infatigable Pontanari», quen coas súas «hábiles» mans e axudándose dalgunhas ferramentas «proporcionadas galantemente en una estación de ferrocarril», solucionou «inmediatamente» o problema xurdido nunha das bicicletas. ${ }^{31}$

\footnotetext{
${ }^{29}$ Gaceta de Galicia, 5 de agosto (1889): 2.

${ }^{30}$ Gaceta de Galicia, 22 de novembro (1894): 2. Xoán Guitián e Ricardo Gurriarán analizaron o alcance desta relación na obra de Valle-Inclán: «O que si existen son elementos que permiten afirmar que Valle-Inclán mantivo viva a lembranza do seu profesor. Cómpre lembrar que en obras de Don Ramón moi distanciadas no tempo aparecen personaxes que teñen por nome Attilio ou Atilio. É o caso do Príncipe Attilio Bonaparte en Epitalamio (1897) e Corte de Amor (1903). En Tirano Banderas (1926) aparece outro personaxe chamado Atilio Palmieri, nome e apelidos que lembran inevitablemente ós de Attilio Pontanari»; Xoán Guitián e Ricardo Gurriarán, «ValleInclán, entre a esgrima e os desafíos, con Pontanari ó fondo", Cuadrante. Revista cultural da Asociación Amigos de Valle-Inclán, no. 15 (2007): 27-41.

${ }^{31}$ Gaceta de Galicia, 4 de setembro (1889): 3; e 12 de outubro (1889): 3; Expediente persoal de Attilio Pontanari Maestrini, AXA, Sección educación, Caixa 32/8440, atado 5859-3; e Mariano Fernández Tafall, «Desde Oporto. 50 leguas en bicicleta», Gaceta de Galicia, 11 de xullo (1891): 1-2. En Porto, Attilio Pontanari visitou a Sociedade de Bombeiros Voluntarios, interesándose por todo o relacionado coas escadas, lámpadas eléctricas, cintos e cascos; e o ximnasio Laurent, que contaba cunha gran dotación de aparellos e máquinas. A Comisión de Propaganda do Ximnasio e Sala de Armas Laurent concedeulle o diploma de profesor honorario.
} 
A habilidade manual, á marxe da espada, foi unha das calidades que caracterizou a Pontanari e con ela procurou beneficiar a sociedade. Xa en 1886 rexistrara a patente da "máquina inodora Attilio Pontanari» para a extracción de materias fecais. ${ }^{32}$ Durante a súa etapa compostelá, no ano 1890, presentou este invento a unha comisión do Concello, momento que aproveitou José Tarrío García para publicar o artigo «Un aparato importante». Nas súas liñas o autor facía unha análise das condicións hixiénicas da cidade, dos seus focos insalubres e dos problemas das canalizacións, e subliñaba que a pesar das investigacións e os informes do "sabio patólogo Sr. Teijeiro" e do Dr. Varela de la Iglesia, os seus esforzos por corrixir esta situación foran infrutuosos. ${ }^{33}$

En todo caso, no eido da ortopedia Pontanari amosouse tan virtuoso coma no resto de facetas. Unha das creacións que espertou maior admiración foi unha perna artificial, fabricada para un canteiro da Coruña que sufrira unha amputación por mor dun tumor. Custeouse mediante unha subscrición e estivo exposta no escaparate dun comercio da rúa Real da cidade herculina. Constaba de tres partes correspondentes á coxa, perna e pé, que se articulaban "por medio de goznes" ${ }^{34}$. Os seus saberes e as súas habilidades foron un acicate para seguir aprendendo e avanzando; durante a estadía en Compostela afondou nos seus coñecementos en relación coa súa faceta hixiénica e sanitaria, e con data do 30 de xaneiro de 1893 aprobou na Universidade de Santiago as materias correspondentes para poder exercer a "carrera de practicante». ${ }^{35}$

A dimensión sanitaria e terapéutica sempre estivo presente nas súas actividades. Adoitou incorporar como alumnos aquelas persoas sen recursos ás que se lles recomendase por prescrición facultativa algún tipo de práctica física ou correctiva. Mantivo este principio incluso na escola ximnástica de verán que abriu en Vilagarcía de Arousa, lugar que escolleu en 1893 para pasar a tempada estival, ao igual que as familias compostelás acomodadas. ${ }^{36}$

Ao finalizar ese verán, o xa mencionado nomeamento de Attilio Pontanari e a súa incorporación ao Instituto de Pontevedra, provocou que os seus pasos se encamiñasen cara á cidade do Lérez. Integrouse rapidamente no seu novo destino, compaxinando a docencia coas clases de esgrima no Liceo de Pontevedra -e exerceu a dirección dos Bombeiros Voluntarios durante a súa breve existencia en 1895-. Tamén continuou formándose, xa que estudou o bacharelato durante o curso 1893-1894 e o seguinte. ${ }^{37}$ Este feito amosa unha situación paradoxal, debida ao sistema de acceso do profesorado de Ximnástica, na que 0 profesor dunha materia carece do grao no que imparte.

\footnotetext{
${ }^{32}$ Boletín Oficial de la Propiedad Intelectual e Industrial, no. 3, 1 de outubro (1886): 9.

${ }^{33}$ Gaceta de Galicia, 14 de marzo (1890): 2; e José Tarrío García, «Un aparato importante», El Telegrama, 13 de setembro (1890): 1.

${ }^{34}$ Gaceta de Galicia, 7 de febreiro (1891): 2-3.

${ }^{35}$ Expediente persoal de Attilio Pontanari Maestrini, AXA, Sección educación, Caixa 32/8440, atado 5859-3.

${ }^{36}$ Gaceta de Galicia, 8 de xullo (1893): 3.

${ }^{37}$ López Fariña, «Attilio Pontanari...», 73-96.
} 
En 1897, ao abrirse o xa citado procedemento para o acceso ao título de profesor oficial de ximnástica, o mestre italiano presentouse aos exames de reválida na Universidade Central e superounos con data de 24 de xuño. ${ }^{38}$

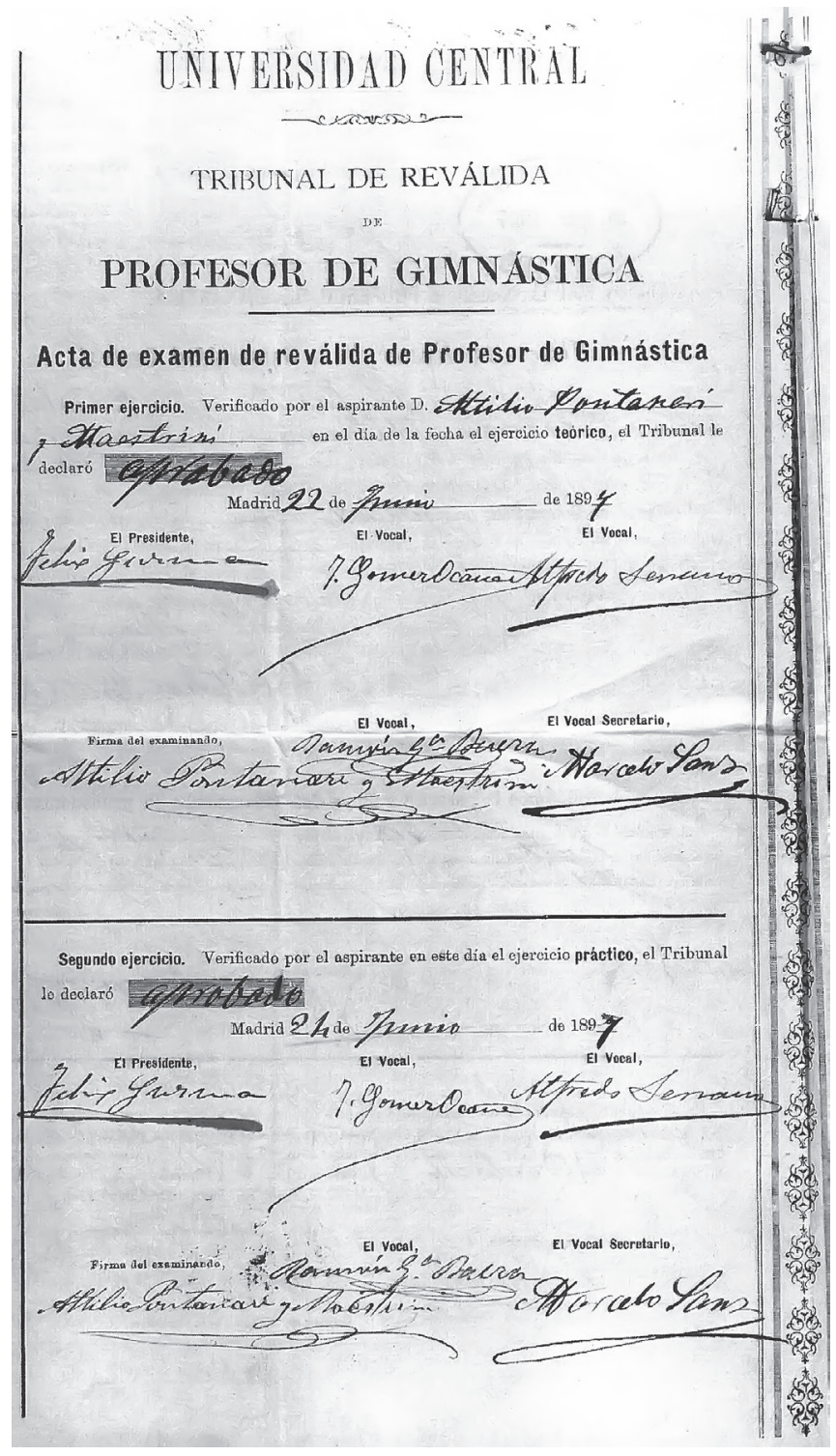

Acta de exame de revalida de Attilio Pontanari Maestrini

${ }^{38}$ Attilio Pontanari Maestrini, Arquivo Histórico Nacional, Sección universidades, atado 1637, Expediente 45. 
Pero a vida de Attilio Pontanari e a súa familia viuse truncada no verán de 1897. 018 de agosto produciuse o pasamento de Eva Pontanari, a filla menor da parella, que acababa de cumprir 15 anos, a causa dunha enfermidade. Durante un tempo a súa actividade tivo continuidade; o profesor atendía as súas clases, exercía tamén de «Practicante, aparatista, instrumentista» do hospital provincial, e incluso de delegado da revista Los Deportes. Ademais, 09 de maio de 1899, en virtude da súa nova condición de profesor oficial, foi nomeado titular do Instituto de Pontevedra. Mais no ano 1900 a situación cambia radicalmente, viaxa a Italia e decide permanecer alí coa súa familia. A decisión é firme e con data de 31 de decembro de 1900 renuncia á súa praza de profesor titular. ${ }^{39}$

Permaneceu no país transalpino até 1907, momento no que regresou a Pontevedra para instalarse de novo na cidade. Nesta ocasión a súa estadía durou tres anos, durante os que puido asumir de novo algunhas das responsabilidades que exercera anteriormente. En 1910 trasladouse a Vigo coa súa familia, onde foi profesor na coñecida e prestixiosa institución El Gimnasio, ademais de xefe de bombeiros. Tamén nesa localidade casou a súa filla Gloria no ano 1914 onde residiu até o seu pasamento o 3 de marzo de 1923, e sería soterrada xunta a súa irmá en Pontevedra. Attilio Pontanari e Emilia Rodríguez permaneceron en Vigo até o momento en que finou o profesor florentino, o 24 de outubro de 1924. A súa inseparábel compañeira acabou instalándose en Ferrol, de onde era orixinaria a súa familia, e alí tocaron a fin os seus días nas postremeiras do ano 1930.

\section{O modelo de formación corporal de Attilio Pontanari}

A faceta de profesor de Attilio Pontanari definiuno profesionalmente -e foi precisamente o tratamento de profesor o empregado con preferencia pola prensa ao mencionalo- pero xerou menos informacións e menos referencias concretas que o seu labor noutros ámbitos. Durante a súa etapa compostelá non constan conferencias nin escritos sobre a súa visión da educación física. Anos máis tarde, despois de acadar o título de profesor oficial, publicou as súas reflexións sobre a ximnasia, concretamente no ano 1898 en El Noticiero Gallego, a través dun artigo dividido en catro partes e titulado "Algo sobre Gimnasia».

Para facer un achegamento ao modelo educativo que puxo en práctica na escola de ximnasia da RSEAP, nunha etapa en que contaba con escasa experiencia profesional e carecía dalgúns dos saberes que, sen dúbida, adquiriu ao preparar a reválida superada en 1897, só cabe analizar as diversas informacións sobre a súa actividade recollidas durante eses anos. Por unha banda, a través dos datos dispoñíbeis sobre 0 ximnasio da RSEAP e o seu funcionamento, publicados na prensa local, nalgúns casos como simples noticias soltas, pero noutros en artigos máis extensos asinados por algún colaborador habitual ou por algún persoeiro da cidade que expón as súas reflexións respecto do traballo de Pontanari; e, pola outra, mediante as novas publicadas sobre unha exhibición organizada a modo de velada en que amosou á cidadanía o seu labor. Esta desenvolveuse no Teatro-Circo instalado na cidade e, tras ser adiada nunha ocasión

${ }^{39}$ Expediente persoal de Attilio Pontanari Maestrini, AXA, Sección educación, Caixa 32/8440, atado 5859-3. 
pola enfermidade dun alumno, foi realizada por «Pontanari y sus discípulos de gimnasia y esgrima» na primavera de $1891 .^{40}$

Nos artigos e informacións que falan das clases de ximnasia na RSEAP constátase unha primeira consideración sobre as calidades de Attilio Pontanari como profesor: a de "peritísimo corrector de defectos físicos». Esta apreciación figura nun artigo publicado na denominada sección editorial de Gaceta de Galicia, titulado "La Gimnasia» e asinado baixo o pseudónimo de Chichito. Nese mesmo artigo tamén se reflicte a utilización durante as clases dun "completo surtido de aparatos", práctica que se realiza baixo a dirección do mestre italiano. A pesar do parco da información confirma, en primeiro lugar, que no seu labor de profesor concedía unha grande importancia ao ámbito corrector da educación corporal (ao igual que fixo no verán de 1893 en Vilagarcía cando, como quedou recollido, abriu as portas da súa sala de ximnasia ás persoas que podían atopar nela solución ou alivio das doenzas que padecían). E, en segundo lugar, que a actividade con axuda de máquinas ou aparellos era unha práctica habitual nas súas clases, feito que non só aparece suxerido no artigo, senón que o evidencia tanto o xa mencionado traslado destes instrumentos desde Barcelona, como algúns dos exercicios realizados durante a exhibición que será analizada deseguido. Pódese colixir, por tanto, que as sesións do profesor Pontanari son clases de ximnasia en sala, o cal non impediría que puidese ter desenvolvido algunha actividade no exterior, mais non existe constancia de ningunha práctica ao aire libre. ${ }^{41}$

Unha colaboración xornalística que achega valiosa información sobre o traballo do mestre italiano é a publicada por José Tarrío García en Gaceta de Galicia, o 24 de outubro de 1890, baixo o título "Gimnasia Higiénica» -autor do artigo "Un aparato importante» citado anteriormente-. No texto o autor salienta os numerosos e «utilísimos» aparatos de que dispón a escola destinados a produciren o desenvolvemento de «músculos determinados»; e de entre eles resalta, polo seu «fácil é ingenioso mecanismo», un dinamómetro para medir a forza adquirida no «lento y gradual» exercicio. Outro dos datos que desvela, ao facer referencia ao elevado número de alumnos de "ambos sexos" cos que xa conta a escola, é que a compañeira de Attilio Pontanari -se ben o seu nome, Emilia Rodríguez, nos se cita no artigo- exercía tamén de profesora. ${ }^{42}$

Unha característica do profesor florentino que descobre o artigo é a de que foi quen de integrar as súas facetas de inventor, ortopedista e ximnasta para aplicalas á praxe educativa; e, a súa vez, que os aparatos empregados contribuían ao desenvolvemento

\footnotetext{
${ }^{40}$ Gaceta de Galicia, 25 de febreiro (1891): 2; 4 de abril (1891): 3; 7 de abril (1891): 3; e 14 de abril (1891): 2-3.

${ }^{41}$ Chichito, «La Gimnasia», Gaceta de Galicia, 10 de setembro (1889): 1. Un artigo idéntico na maioría dos seus parágrafos ao publicado baixo o pseudónimo de Chichito apareceu tamén na sección editorial de Gaceta de Galicia, o 28 de novembro de 1890, co seguinte título: «La Escuela de Gimnasia en la Sociedad Económica». Nesta ocasión a colaboración está asinada por A. T. Rivas, quen moi probabelmente foi tamén autor do publicado un ano antes.

${ }^{42}$ José Tarrío García, "Gimnasia Higiénica», Gaceta de Galicia, 24 de outubro (1890): 1. José Tarrío García, xornalista e político, integrouse en 1890 no Comité Central Rexionalista presidido por Manuel Murguía, e despois formou parte da Asociación Rexionalista Galega. Foi elixido concelleiro na cidade de Santiago de Compostela en 1891. Ademais, foi o responsábel, xunto a Enrique Labarta Pose, de dirixir a revista La Pequeña Patria.
} 
da forza muscular. Evidénciase o feito de que a súa creatividade, unida tanto á súa habilidade no taller como á súa propia experiencia de home fisicamente cultivado, lle permitía, sen necesidade de grandes medios, trasladar á aula e ao ximnasio a súa bagaxe vital. Esa experiencia persoal arredor da esgrima, a forza, os deportes de combate, a ximnasia acrobática e a que cabe denominar ximnasia de exhibición -mestura de forza e acrobaciaconstituía o alicerce da súa docencia.

A achega de José Tarrío constata tamén a existencia dunha clase de ximnasia específica para nenas, e aínda que o seu desenvolvemento tivese lugar de xeito separado e a súa responsábel fose unha muller, Emilia Rodríguez, o feito da súa posta en marcha estaba a rachar coa visión que a sociedade da época proxectaba, e impoñía, sobre o sexo feminino -que mantiña a muller afastada da educación, do coñecemento e, por suposto, de todas aquelas actividades consideradas masculinas-. A presenza e participación das mulleres en actividades ximnásticas, e en xeral na educación física, xa fose na faceta de alumnas xa fose na de profesoras -neste sentido a mencionada Escuela Central de Profesores y Profesoras de Gimnástica foi unha institución innovadora- sitúa o ámbito da formación corporal entre os primeiros espazos sociais que aglutinan no seu seo ambos os sexos. Non en igualdade, pois aínda quedaba un longo e difícil camiño que percorrer, mais si como un dos primeiros pasos.

No que respecta ás actividades concretas que Attilio Pontanari dirixía na escola de ximnasia, a velada no "Teatro-Circo», celebrada alí grazas á cortesía dos seus propietarios, é a que en maior medida proporciona información. Familias e un gran número de estudantes asistiron á función que, para a súa posta en escena, contou coa colaboración desinteresada da orquestra dirixida polo «notable violinista Sr. Curros». A exhibición constou de dezasete números diferentes, aínda que o peso principal da sesión recaeu na esgrima e a loita. ${ }^{43}$

Os tres primeiros, que poden encadrarse nesa liña, foron un «asalto de florete», unha demostración de loita con "bastón de calle» e un espectáculo de «boxeo». A cuarta actuación, presentada como unha "sorpresa», consistiu nunha representación realizada por "Gloria y Eva Pontanari, vestidas de guerreros antiguos, con cota de malla y casco aviserado"; así caracterizadas foron cambiando a "figura» un total dunhas vinte veces, representando feitos históricos. Despois, celebrouse un "asalto de sable y florete» e seguidamente entraron en escena tres dos máis «distinguidos» ximnastas que, mentres danzaban ao "son de una polka» e sen perderen o compás, realizaron "la mar de saltos, cabriolas, planchas, y chistes mímicos de primer orden». Os tres ximnastas atenderon a solicitude do público, que segundo conta a crónica non cesou de rir, e repetiron os exercicios. ${ }^{44}$

O sétimo número correspondeulle á orquestra do "Centro Escolar» que interpretou algunhas pezas do seu repertorio; e os dous seguintes foron dúas novas demostracións de loita, primeiro un «asalto de sable», no que tomou parte Pontanari, e despois un «asalto de

${ }^{43}$ Gaceta de Galicia, 25 de febreiro (1891): 2; 4 de abril (1891): 3; 7 de abril (1891): 3; e 14 abril (1891): 2 e 3.

${ }^{44}$ A. Mosquera, «En el circo», Gaceta de Galicia, 14 abril (1891): 2 e 3. 
palo largo». A décima actuación foi un exercicio hixiénico realizado polos nenos da escola de ximnasia sobre o que non se achegan datos. De entre as tres seguintes postas en escena, dúas foron exhibicións de forza do propio Attilio Pontanari consistentes, respectivamente, en dobrar a "fuerza de golpes» unha barra de ferro e en elevar e facer diversos exercicios con outra barra de gran peso. No medio de ambas as demostracións de forza realizaron exercicios sobre as paralelas os alumnos de ximnasia da «Económica, y de distintas facultades en la Universidad».

As pequenas Gloria e Eva Pontanari foron as protagonistas da décimo cuarta actuación, consistente nun «asalto de espada italiana», e ao finalizar o seu número recibiron obsequios de "D. Ramiro Rueda» -director da RSEAP-e doutras familias e personalidades da cidade. A continuación, crearon "pirámides humanas" os alumnos de ximnasia que, segundo sinala a crónica, evidenciaron as dotes que «como profesor de aquel arte-ciencia, (como algunos le llaman) posee el Sr. Pontanari». Finalmente, tras unha demostración de loita "romana» e transcorridas tres horas, rematou a velada co número das escadas "encantadas» no que participaron todos os ximnastas e Attilio Pontanari, quen facía de base no medio das dúas escadas, sostendo «en ellas y sobre si, más de ocho y diez de sus discípulos».

Esta esquemática mostra do traballo que estaba a desenvolver o mestre italiano reflicte o que foron os inicios da ximnasia en Compostela. Identificar de xeito xenérico o contido da exhibición coa actividade cotiá da escola dirixida por Pontanari sería unha especulación. Ora ben, resulta incuestionábel a lóxica relación entre o día a día das sesións e os números presentados. Así tamén, o feito de que a súa preparación tivo que requirir da meirande parte do tempo dispoñíbel durante un considerábel número de xornadas.

A esgrima e a loita conforman as prácticas centrais, seguidas das habilidades ximnásticas e das demostracións de forza. Isto, unido á información proporcionada polo artigos presentados, permite encadrar o modelo de educación corporal do profesor florentino na órbita do denominado Movemento Ximnástico do Oeste, xurdido en Francia arredor de Francisco Amorós e con importante proxección en Italia..$^{45} \mathrm{Na}$ súa posta en práctica prodúcese unha adaptación da carga e a intensidade en función da idade dos ximnastas, mais as actividades son as realizadas na idade adulta. Isto é, o alumnado non conforma un grupo con características propias, determinadas tanto pola súa singularidade como pola súa etapa de desenvolvemento, senón que é considerado equiparábel aos adultos, coa premisa que cómpre ter presente de que o seu corpo aínda non acadou a plenitude.

Cabe apuntar que ao mesmo tempo que Attilio Pontanari orientaba a súa praxe segundo o modelo aprendido na escola florentina, na liña do Movemento do Oeste, esta corrente estaba a ser renovada por Etiene Jules Marey e Georges Demeny, por un lado, e

\footnotetext{
${ }^{45}$ Giner de los Ríos era gran coñecedor da obra de Amorós que analizou nun dos seus escritos; e como xa se indicou o institucionismo sempre se situou a favor doutro modelo de educación corporal. Vid. Francisco Giner de los Ríos, «D. Francisco Amorós. Fundador de la gimnasia francesa», Ensayos Menores sobre Educación y Enseñanza, tomo II (en Obras completas de Francisco Giner de los Ríos, t. XVII) (Madrid: Espasa-Calpe, 1927), 245-275.
} 
por Fernand Lagrange e Philippe Tissié por outro (este último foi o inspirador das experiencias ximnásticas desenvolvidas anos despois pola xa mencionado profesor Revuelta en Compostela). Tamén é importante subliñar que a formación do profesorado de Ximnástica, que a partir de 1893 vai iniciar o seu labor docente nos institutos, estivo enmarcada no mesmo modelo.

Certamente, o proceso a través do que se xestou a primeira escola ximnástica compostelá, respondeu a un pensamento máis moderno e innovador do que foi o seu contido práctico unha vez posta en marcha. Non obstante, tamén tivo luces extraordinarias como foron o compromiso educativo con ambos os dous sexos e o esforzo por promover e popularizar a formación corporal.

A partir do peche da escola de ximnasia da RSEAP, a actividade corporal na cidade non volveu ocupar un espazo central até despois de 1903; agás con motivo da censura do libro de texto de Ximnástica do Instituto, decretada polo arcebispo da diocese de Santiago, José Martín de Herrera de la Iglesia, que xerou unha fonda polémica. ${ }^{46}$

\section{Un apuntamento final}

O mestre italiano, o profesor florentino, o Hércules, o ortopedista, o ciclista, o inventor, o xefe de bombeiros, todos son Attilio Pontanari Maestrini. Home que unanimemente definen as crónicas como vital, afábel, simpático e xeneroso. Tamén foi o entrañábel e ferido pai que sufriu, xunto a súa compañeira Emilia Rodríguez Fariña, o quebranto do pasamento da pequena Eva cando aínda era unha nena; e xa nos anos postremos, tamén 0 de Gloria.

Pontanari, galego de adopción e eternamente pontevedrés, quedou unido ao cemiterio de San Mauro de xeito indelébel. Despois de ter traballado e loitado tanto e tan xenerosamente finou pobre, até tal punto de que a súa compañeira non puido trasladar o seu cadáver a Pontevedra para ser soterrado na foxa das súas fillas, como era o desexo do profesor, e tivo que ficar en Vigo. ${ }^{47}$

Xa que non fisicamente, perdure e descanse de forma simbólica na nosa memoria, 0 profesor Attilio Pontanari Maestrini, no camposanto de San Mauro.

\footnotetext{
${ }^{46}$ José Luis Antas Ramos, «La elección de un texto escolar en el Instituto de Santiago: un conflicto entre el dogma católico y el conocimiento durante el curso 1893-1894", en Alfredo Jiménez Eguizábal... [et al.], Etnohistoria de la escuela. XII Coloquio Nacional de Historia de la Educación (Burgos: Universidad de Burgos, 2003), 477-488.

${ }^{47}$ "Atilio [sic] Pontanari», El Diario de Pontevedra, 28 de outubro (1924): 1.
} 